\title{
Genetic parameters of a random regression model for daily feed intake of performance tested French Landrace and Large White growing pigs
}

\author{
Urs SCHNYdeR $^{\mathrm{a} *}$, Andreas Hofer ${ }^{\mathrm{a}}$, \\ Florence LABROUE ${ }^{\mathrm{b}}$, Niklaus KÜNZI ${ }^{\mathrm{a}}$

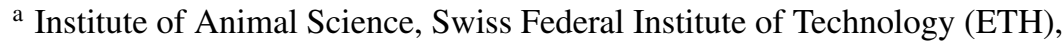 \\ 8092 Zurich, Switzerland \\ ${ }^{\mathrm{b}}$ Institut technique du porc, La Motte au Vicomte, \\ BP 3, 35651 Le Rheu Cedex, France
}

Some misprints appeared on page 640 , in Table II and in the last paragraph of Section 2.2 (line 9). One should read : "3.075 $\times 10^{-2}$ ", " $-4.900 \times 10^{-4}$ ", " $1.440 \times 10^{-5}$ ", " $2.500 \times 10^{-9}$ " and " $1.0 \times 10^{-8}$ ", respectively (there are not exponential functions).

* Correspondence and reprints present address: Swiss Brown Cattle Breeders' Federation, Chamerstrasse 56, 6300 Zug, Switzerland.

E-mail: urs.schnyder@braunvieh.ch 